\section{OP-04 EVALUATION OF THE JANANI SHISHU SURAKSHA KARYAKRAM: FINDINGS ON INEQUITY IN ACCESS FROM CHHATTISGARH, INDIA}

Sulakshana Nandi, Dipa Sinha, Deepika Joshi, Rajesh Dubey, Vandana Prasad. PHRN - Public Health Resource Network, New Delhi (Delhi NCR), India

10.1136/bmjgh-2016-EPHPabstracts.4

Background Chhattisgarh is one of the poorer states in India, having a large tribal population, with infant mortality rate of 48 and maternal mortality ratio of 230. The Janani Shishu Suraksha Karyakram (JSSK) initiated in 2011 by the government of India aims to provide free maternal and neonatal services in all public health institutions in order to encourage institutional deliveries, and thereby reduce infant and maternal mortality. This study attempts to understand the functioning of JSSK in Chhattisgarh and to what extent it has been able to fulfil its objective in the state, specifically with respect to coverage of vulnerable groups.

Methods Our study was a mix of quantitative and qualitative research. A total of 511 women $(53 \%$ ST - Scheduled Tribes, 35\% SC - Scheduled Castes, 9\% OBC - Other Backward Castes category), who had delivered or terminated pregnancy in last six months, were interviewed using a structured interview schedule in selected villages of two tribal (Sarguja and Bastar) and one non-tribal district (Mahasamund). Facility survey was conducted in 16 health facilities and programme data were reviewed. Ethical clearance was provided by the Institutional Ethics Committee of the Public Health Resource Society.

Findings Coverage of antenatal care services was quite high with $84 \%$ of the women having attended at least three antenatal care visits. However, the quality of antenatal care services was better in the non-tribal district compared to the two tribal districts. Most of the antenatal care visits occurred in public services, with higher proportions in the tribal districts. Institutional delivery was $72 \%$. Half of women who delivered at home wanted to go for institutional delivery but could not do so due to several barriers. The proportion of institutional deliveries was lowest among the tribal (62\%) and non-literate respondents $(60 \%)$. Of the institutional deliveries, $85 \%$ were conducted in public facilities with higher proportions (93\% and 96\%) in the tribal districts. Availability of free transport to the facility was found to be high for people who called for it while return transport was provided to $60 \%$ of women who delivered at a public facility. These percentages were higher for tribal districts. Free food was provided to $55 \%$ of women. Referral transport to a higher public facility was not ensured in all cases. Though most of the facilities surveyed are undertaking deliveries, huge gaps were identified in preparedness for dealing with both basic deliveries and emergencies. These gaps include non-availability of essential medicines and/or blood bank/storage facility in most of the community health centres. None of the community health centres surveyed had a gynaecologist nor adequate facilities for C-section. Out-of-pocket expenditure was incurred by $98 \%$ of women who went to a private facility and by $56 \%$ of women going to a public facility. In private facilities, median out-of-pocket expenditure (INR 6,400) was ten times higher than in public facilities (INR 640). Even though half of the women had insurance cards under Rashtriya Swasthya Bima Yojana or Mukhyamantri Swasthya Bima Yojana, only 16 women made use of these schemes. Out of these 16 women, 12 still incurred out-of-pocket expenditure.

Discussion and recommendations Our study shows that the public health system has to an extent been made more accessible to the community, including vulnerable groups, for delivery services in Chhattisgarh. However, gaps still remain, especially with respect to quality of services, out-of-pocket expenditures and functionality of Rashtriya Swasthya Bima Yojana and Mukhyamantri Swasthya Bima Yojana. This has often led to people, especially from the more vulnerable social groups, being excluded from utilising the services and schemes. It is evident that the public health system is the dominant sector providing services related to pregnancy and delivery, especially to the vulnerable groups. Therefore, it is critical that the public health facilities are adequately resourced for providing free, safe and quality health services. The state's initiatives in providing human resources for remote rural areas, like the Chhattisgarh Rural Medical Corporation, posting Rural Medical Assistants, scholarships to Mitanins (women community health workers) from underserved districts for auxiliary nurse midwife and nursing courses need to be strengthened. Institutions like the Chhattisgarh Medical Services Corporation need to improve their functioning in assuring timely and adequate supplies of medicines and consumables. The government needs to show its commitment to health through increased funding and efficacious systems of accountability and grievance redressal. It is hoped that this study will help civil society and the government to focus on the critical gaps and address them urgently for better and more equitable maternal and neonatal health.

Grant funding (Oxfam India, New Delhi) for research but no other competing interests. 